\title{
Políticas de Educação Integral em Tempo Integral à Luz da Análise do Ciclo da Política Pública
}

\begin{abstract}
Cláudia da Mota Darós Parente'
'UniversidadeEstadual Paulista Júlio de Mesquita Filho (UNESP), Marília/SP-Brasil

RESUMO - Políticas de Educação Integral em Tempo Integral à Luz da Análise do Ciclo da Política Pública. O presente artigo tem como objetivo sistematizar alguns elementos para a análise das políticas de educação integral em tempo integral considerando o ciclo da política pública. O ciclo de uma política pública é composto pelas seguintes fases: agenda, formulação, implementação e avaliação. Por meio de um ensaio teórico, embasado na bibliografia da área de políticas públicas e no acúmulo teórico e empírico acerca da temática, o presente estudo mostra como as políticas de educação integral em tempo integral apresentam-se atualmente na agenda político-educacional brasileira e como vêm sendo formuladas, implementadas e avaliadas. Aponta a relevância de se construir instrumentos e metodologias de análise que melhor captem as necessidades da área.

Palavras-chave: Educação em Tempo Integral. Política Educacional. Ciclo de Políticas Públicas.
\end{abstract}

ABSTRACT - Full-time and Integral Education Policies Considering the Public Policy Cycle Analysis. This article aims to systematize some elements for the analysis of full-time and integral education policies considering the public policy cycle. The public policy cycle is composed of the following phases: agenda, formulation, implementation and evaluation. Through a theoretical essay, based on the bibliography of the public policy area and the theoretical and empirical accumulation about the subject, the present study shows how full-time and integral education policies are currently on the Brazilian political-educational agenda and how they have been formulated, implemented and evaluated. It points out the relevance of constructing analytical tools and methodologies that better capture the needs of the area.

Keywords: Full-time Education. Educational Policy. Public Policy Cycle.

Educação \& Realidade, Porto Alegre, v. 43, n. 2, p. 415-434, abr./jun. 2018. 415 http://dx.doi.org/10.1590/2175-623661874 
Políticas de Educação Integral em Tempo Integral...

\section{Introdução}

A política pública é geralmente conceituada como o Estado em ação, ou seja, a ação do Estado propriamente dita (Jobert; Müller, 1990). É a área do conhecimento "[...] que busca, ao mesmo tempo, 'colocar o governo em ação' e/ou analisar essa ação [...] e, quando necessário, propor mudanças no rumo ou curso dessas ações [...]" (Souza, 2006, p. 25). No entanto, há autores que definem a política pública também como aquilo que o Estado não faz e deveria fazer, "[...] tudo o que os governos escolheram fazer ou não fazer" (Dye, 2008, p. 1, tradução nossa) ${ }^{1}$.

No que se refere à educação integral em tempo integral, em virtude das descontinuidades de proposições ao longo da história da educação brasileira, comumente, diz-se que não houve política pública na área. Essa expressão, na verdade, denota que a ação do Estado foi pouco efetiva em relação à questão. No entanto, compreende-se que a ação do Estado pode mostrar-se de forma mais ou menos contínua, efetiva e legítima, por meio de programas mais ou menos estruturados, com grandes ou pequenos impactos a depender da maneira como são articulados os interesses dos atores envolvidos no processo de decisão política.

É possível conceituar política pública a partir de uma abordagem estadocêntrica ou multicêntrica, caso se considere o monopólio de atores estatais na elaboração das políticas ou a participação de outras organizações privadas e não governamentais em sua elaboração, respectivamente (Secchi, 2014). Assim, com base na abordagem multicêntrica, que compreende a multiplicidade de atores que participam nesse processo de tomada de decisão, no que se refere às políticas educacionais, tem sido cada vez mais visível a participação de diferentes atores na definição dos rumos da educação brasileira. Isso também ocorre no que se refere às políticas de educação integral em tempo integral.

Os modelos de ampliação da jornada escolar e de educação em tempo integral são resultados da construção de diferentes atores, ou seja, há uma multiplicidade de atores e instituições delineando alternativas e possibilidades de construção de uma escola ampliada. Isso é decorrente da ação do Estado, mas a ação do Estado, na configuração das políticas públicas, não ocorre de forma isolada; tem recebido diferentes intervenções de diversos segmentos da sociedade e de instituições públicas e privadas.

Portanto, adotamos aqui um conceito de política pública que se associa à abordagem multicêntrica; há inúmeras políticas de educação integral em tempo integral sendo delineadas por diferentes instâncias de governo (União, estados, Distrito Federal, municípios), porém configuradas com a participação, negociação e indução de diferentes esferas públicas e privadas. Isso pode ser corroborado pela diversidade de políticas de educação integral em tempo integral existentes atualmente no Brasil: políticas de educação integral em tempo integral formuladas e implementadas no mesmo âmbito administrativo ou por diferentes esferas administrativas; políticas de educação integral em tempo integral implementadas com recursos públicos ou com recursos públicos $\mathrm{e}$ 
privados; políticas de educação integral em tempo integral implementadas no âmbito da Secretaria de Educação ou intersetorialmente; políticas de educação integral em tempo integral implementadas pelo Poder Público ou por meio de parcerias público-privadas (Parente, 2016a).

Diante dessa concepção, defende-se que o Estado, nas diferentes esferas administrativas, tem o papel de assumir a coordenação dessa política de educação integral em tempo integral, a fim de que a articulação tempos escolares (a exemplo do tempo integral) e tempos de vida de fato ocorra e que os diferentes sujeitos da educação tenham seus direitos garantidos para vivenciar tempos justos e humanos de escolarização (Arroyo, 2004; Parente, 2010; 2015).

No que se refere à distinção entre política de Estado e política de governo, comumente, aquelas políticas que não possuem perspectivas de continuidade para além dos mandatos são chamadas de políticas de governo; e aquelas pautadas em medidas de continuidade, geralmente fortalecidas por ações legais, por planejamento a longo prazo, para além de mandatos e pautadas na participação e no interesse geral da população, são chamadas de políticas de Estado. Com base nessa breve diferenciação, é possível encontrar diversos programas e ações de ampliação da jornada escolar, ora caracterizados como políticas de governo, ora como políticas de Estado. O Programa Mais Educação, por exemplo, ação do governo federal, criado pela Portaria Interministerial $\mathrm{n}^{\circ}$ 17/2007 e reafirmado por meio do Decreto $\mathrm{n}^{\circ}$ 7.083/2010 (Brasil, 2007a; 2010a), com o objetivo de difundir ações de ampliação da jornada escolar, pode ser caracterizado como política de governo, por sua vulnerabilidade às questões orçamentárias, administrativas e políticas (Parente, 2016b).

Para além do Programa Mais Educação é possível identificar na agenda educacional nacional prescrições em relação à educação integral em tempo integral (Parente, 2017), seja no âmbito da legislação, dos planos de educação, dos programas de governo ou mesmo das ações que, juntas, demonstram a atenção dada à questão. Assim, é visível a existência de políticas de educação integral em tempo integral no país, e suas características modificam-se a depender de questões conjunturais e estruturais da educação e da própria sociedade brasileira.

Conforme Dye (2008, p. 4, tradução nossa)2, "análise de política é descobrir o que os governos fazem, porque fazem e que diferença isso faz, se houver". Assim, por meio da análise de política pública pode-se, por exemplo, descrever o que governo faz na área da educação, buscar entender as causas e os determinantes de certa política educacional e avaliar as consequências dessa mesma política na população-alvo.

O fato é que, no que se refere à análise de políticas públicas, existem diferentes caminhos a serem percorridos. De acordo com Souza (2006, p. 28) “[...] alguns modelos explicativos foram desenvolvidos para se entender melhor como e por que o governo faz ou deixa de fazer alguma ação que repercutirá na vida dos cidadãos". Uma das possibilidades analíticas seria considerar o ciclo da política pública ou suas fases como um exercício para melhor compreendê-las. Essa tipologia de análise 
Políticas de Educação Integral em Tempo Integral...

"[...] vê a política pública como um ciclo deliberativo, formado por vários estágios e constituindo um processo dinâmico e de aprendizado" (Souza, 2006, p. 29).

Analisar as políticas por meio da compreensão de uma ou mais fases ou por meio de seu ciclo é, portanto, uma opção metodológica. Existem outras opções metodológicas. No entanto, racionalizar a política pública por meio de seu ciclo não significa defender que a política segue necessariamente as etapas definidas racionalmente. A divisão da política em fases é um exercício de análise de política pública. Em que pese as diferentes formas de conceber as fases da política pública, podese didaticamente nomeá-las de: agenda, formulação, implementação e avaliação (Viana, 1996; Parente; Mattos; Rus Perez, 2012).

A política pública pode ser compreendida como uma ação do Estado para o enfrentamento de determinado problema público. "Um problema é a discrepância entre o status quo e uma situação ideal possível. Um problema público é a diferença entre o que é e aquilo que se gostaria que fosse a realidade pública" (Secchi, 2014, p. 44). Partindo-se desse pressuposto, a educação integral em tempo integral pode ser vista como uma alternativa ao enfrentamento de um problema público, por exemplo, a necessária melhoria da qualidade da educação básica. No entanto, nem sempre a educação integral em tempo integral foi tratada como política pública associada diretamente à melhoria da qualidade da educação básica.

Atualmente, não há um único problema público que justifique a educação integral em tempo integral. Problemas como vulnerabilidade social, trabalho infantil e outras questões sociais também são vistos como problemas a serem enfrentados por meio da ampliação da jornada escolar. Há, portanto, uma série de problemas públicos, no âmbito dos vários entes federativos, que podem justificar a formulação de políticas públicas que prezam pela implantação da jornada escolar em tempo integral.

Por outro lado, é possível que uma política pública de educação integral em tempo integral seja formulada sem necessariamente querer atacar um problema, até porque, muitas vezes, as soluções surgem antes dos problemas.

Conforme Secchi (2014, p. 51-52), existem três formas de entender a dinâmica de escolha de alternativas:

1. Os tomadores de decisão têm problemas em mãos e cor-
rem atrás de soluções [...].
2. Os tomadores de decisão vão ajustando os problemas às
soluções, e as soluções aos problemas [...].
3. Os tomadores de decisão têm soluções em mãos e cor-
rem atrás de problemas [...].

Frente a essas possibilidades, entende-se que nem sempre a formulação de políticas de educação integral em tempo integral é realizada após um rigoroso diagnóstico e com o objetivo de solucionar determinado problema educacional ou social. É possível que a formulação e a 
implementação de determinada política pública despertem discussões de ordem pedagógica, administrativa e financeira, que levem os gestores a associarem ações em andamento a problemas existentes. Essa é a dialética da política pública, da educação e da gestão da educação.

Com base nessas considerações iniciais, o presente artigo tem como objetivo sistematizar alguns elementos para a análise das políticas de educação integral em tempo integral à luz do ciclo das políticas públicas. Isso será feito por meio de um ensaio teórico, embasado na bibliografia da área de políticas públicas e em nosso acúmulo teórico e empírico acerca das políticas de educação integral em tempo integral.

\title{
Fase da Agenda: como a educação integral em tempo integral entra na agenda político-educacional
}

Estudos sobre os ciclos de políticas públicas destacam John W. Kingdon, Roger Cobb e Charles Elder como principais referências no que se refere à caracterização da montagem da agenda das políticas públicas, seus tipos e fatores que influenciam em sua construção (Viana, 1996; Howlett; Ramesh; Perl, 2013; Secchi, 2014).

A montagem da agenda é "[...] o primeiro, e talvez o mais crítico, dos estágios do ciclo de uma política pública, se refere à maneira como os problemas surgem ou não enquanto alvo de atenção por parte do governo" (Howlett; Ramesh; Perl, 2013, p. 103).

Afinal, "por que alguns problemas aparecem na agenda governamental como objetos de ação e outros não?" (Howlett; Ramesh; Perl, 2013, p. 103). A agenda é permeável a inúmeros fatores estruturais e conjunturais. Os temas ou problemas que integram a agenda são resultado de uma série de articulações entre os diferentes atores e instituições.

A agenda pode então ser conceituada como:

\begin{abstract}
[...] a lista de temas ou problemas que são alvo em dado momento de séria atenção, tanto da parte das autoridades governamentais como de pessoas de fora do governo, mas estreitamente associadas às autoridades. [...] Dentro dos possíveis temas e problemas aos quais os governantes poderiam dedicar atenção, eles se concentram em alguns e não em outros (Kingdon, 2006a, p. 222).
\end{abstract}

Entre as várias formas de classificar a agenda, Secchi (2014, p. 46) cita a agenda política, descrevendo-a como "o conjunto de problemas ou temas que a comunidade política percebe como merecedor de intervenção pública", e agenda formal como aquela "que elenca os problemas ou temas que o poder público já decidiu enfrentar".

Vários elementos podem interferir na inclusão, exclusão e manutenção de determinadas questões na agenda: recursos financeiros, recursos humanos, vontade política e pressão dos meios de comunicação e dos setores envolvidos (Subirats, 2006).

Num país federativo como o Brasil, além do aspecto conjuntural, há que se considerar a existência dos diferentes tipos de agendas na 
Políticas de Educação Integral em Tempo Integral...

área da educação que, por vezes, se articulam e, outras vezes, se contrapõem. É o caso das agendas no âmbito nacional, estadual, distrital, municipal e também internacional.

Considerando os apontamentos sobre a agenda, é fundamental discorrer sobre como a temática da educação integral em tempo integral apresenta-se na agenda político-educacional e quais alternativas e/ou modelos de ampliação da jornada escolar estão sendo discutidos como possibilidades de uma educação integral em tempo integral.

A temática da educação integral em tempo integral já ocupou a agenda político-educacional por diversas vezes, a exemplo de discussões, no âmbito local e/ou nacional, em defesa da universalização da escola em tempo integral e que culminou na formulação de experiências como os Centros Integrados de Educação Pública (CIEP) (Cavaliere; Coelho, 2003) e os Centros de Atenção Integral à Criança e ao Adolescente (CAIC) (Amaral Sobrinho; Parente, 1995), surgidos nas décadas de 1980 e 1990, respectivamente. No contexto de discussão da Lei de Diretrizes e Bases, aprovada em 1996 (Brasil, 1996), e do Plano Nacional de Educação (PNE), aprovado em 2001 (Brasil, 2001), a questão também ressurgiu. Embora, historicamente, tenha sido possível visualizar momentos de maior ou menor atenção a ela, pode-se afirmar que é temática que, ao longo do século XX, veio à tona por diversas vezes.

Pode-se afirmar que a educação em tempo integral é temática recorrente na agenda política da educação brasileira. No entanto, nem sempre o tema recebeu força política suficiente para avançar rumo à formulação e à implementação de políticas. Algumas vezes, as políticas na área foram formuladas e implementadas de forma isolada, por alguns entes federativos; e muitas dessas políticas foram permeadas de descontinuidades, aspecto muito presente na gestão pública brasileira (Parente, 2017, p. 23).

A temática da educação integral em tempo integral faz parte atualmente da agenda político-educacional em âmbito nacional, tendo em vista a aprovação da meta 6 do PNE relativa à oferta de "[...] educação em tempo integral em, no mínimo, 50\% (cinquenta por cento) das escolas públicas, de forma a atender, pelo menos, $25 \%$ (vinte e cinco por cento) dos (as) alunos (as) da educação básica” (Brasil, 2014).

\begin{abstract}
A (re)introdução da educação em tempo integral na agenda, sua permanência e seu avanço para as outras fases da política pública dependem de uma série de elementos que atuam como condicionantes da política. [...] a elaboração de uma meta específica de educação em tempo integral no Plano Nacional de Educação de 2014 materializou-se como uma 'janela política' importante para alavancar políticas públicas na área (Parente, 2017, p. 25).
\end{abstract}

Tendo em vista as múltiplas agendas decorrentes dos diferentes níveis de governo e de suas conjunturas específicas, é possível descrever alguns determinantes e ou condicionantes político-legais que influenciaram e vêm influenciando a construção de políticas de edu- 
cação integral em tempo integral: a criação do Fundo de Manutenção e Desenvolvimento da Educação Básica e de Valorização dos Profissionais da Educação (Brasil, 2006; 2007b), em virtude de ter estabelecido ponderações específicas no que se refere às etapas, modalidades e aos tipos de estabelecimentos, incluindo as matrículas em tempo integral; o Programa Mais Educação, criado em 2007, que disseminou e vem disseminando, entre outros elementos, a criação de territórios educativos, o uso de espaços educativos não escolares para desenvolvimento das chamadas atividades complementares e a incorporação de outros profissionais para o desempenho da ação educativa; o Censo Escolar e sua forma de captação das matrículas em tempo integral, englobando as chamadas atividades complementares (Parente, 2016a). Esses determinantes, entre outros, têm sido responsáveis não apenas por colocar e/ou manter a temática na agenda dos diferentes entes federativos, mas também por disseminar certas alternativas e modelos de educação integral em tempo integral, a exemplo das políticas que fazem uso de diferentes espaços educativos, escolares e não escolares e que se utilizam de diferentes profissionais da educação, incluindo voluntários.

Assim, tomando como exemplo o Programa Mais Educação, sabe-se que o governo federal incorporou em sua agenda o desejo de enfrentar o problema da qualidade do ensino fundamental e da ampliação das oportunidades educativas e, para isso, formulou o referido Programa. Sua implementação nos estados, Distrito Federal e municípios, por meio do repasse de recursos financeiros, bem como as repercussões do PNE podem fazer com que esses entes federativos também incorporem em suas agendas a temática da educação integral em tempo integral. No entanto, tudo vai depender de como os atores das diferentes esferas governamentais interagem.

Em tese, todos os cidadãos comuns podem atuar politicamente. No entanto, existem atores que possuem maior força política para inserirem, manterem ou retirarem determinados temas e/ou problemas da agenda. De acordo com Kingdon (2006b, p. 230), são os chamados participantes visíveis, representados pelo Presidente, pelos membros do Congresso e do alto escalão do governo e pela mídia, que definem a agenda. Assim, “[...] as chances de um tema ganhar visibilidade na agenda governamental aumentam se este for levantado por participantes do grupo visível [...]".

No âmbito da educação não poderia ser diferente. A definição da agenda político-educacional tem sido feita pelo Legislativo e pelo Executivo. No âmbito da educação integral em tempo integral, cabe destacar o Ministério da Educação como

[...] ator institucional de grande relevância [...]. A presença marcante da discussão sobre a educação em tempo integral no Documento-Referência da Conae/2010, elaborado pelo Ministério da Educação, é reflexo da política que vinha sendo desenvolvida desde 2007, no contexto do Plano de Desenvolvimento da Educação, por meio do Programa Mais Educação. Esse contexto político-educacional criou 
Políticas de Educação Integral em Tempo Integral...

as condições necessárias para a materialização de uma meta específica de educação em tempo integral, ou seja, uma importante 'janela política' para o fortalecimento e manutenção da temática na agenda política (Parente, 2017, p. 38).

Assim, pode-se dizer que são muitas as variáveis que interferem nas possibilidades de colocar, manter ou retirar a temática da educação integral em tempo integral da agenda educacional. A temática está na agenda educacional atualmente. E isso tem levado à formulação e à implementação de políticas em diferentes esferas de governo. No entanto, infelizmente, não há como garantir que a temática permaneça na agenda; não há como garantir que sua manutenção na agenda repercutirá na formulação de políticas efetivas para a área.

\section{Fase da Formulação: como as políticas públicas de educação em tempo integral são formuladas}

De acordo com Howlett, Ramesh e Perl (2013, p. 123), “[...] a formulação da política pública refere-se ao processo de criação de opções sobre o que fazer a respeito de um problema público". Para Secchi (2013, p. 48), a formulação de políticas ou formulação de alternativas, “[...] é o momento em que são elaborados métodos, programas, estratégias ou ações que poderão alcançar os objetivos estabelecidos. Um mesmo objetivo pode ser alcançado de várias formas, por diversos caminhos".

Nessa complexa fase de seleção de uma alternativa entre várias outras para a solução de um problema público (numa visão linear), é importante compreender como ocorre o processo decisório, quais os atores e instituições envolvidas e os limites da racionalidade no processo de tomada de decisão política. Lindblon (1981) faz relevantes apontamentos sobre esses elementos.

Numa visão unidirecional, a tomada de decisão vem logo após a formulação de alternativas para a solução de determinado problema público que se encontrava na agenda. Considerando a política pública de forma racional, o processo de tomada de decisão pode ser visto como uma escolha realizada diante de várias alternativas, com base em critérios específicos, de modo a atingir determinado problema.

No entanto, há que se considerar, conforme apontado anteriormente, que às vezes as soluções surgem antes dos problemas; muitos gestores pensam em inovações, criam determinadas ações e, secundariamente, pensam nos problemas que podem se beneficiar com tais ações. Muitas vezes, são formuladas políticas sem que temáticas específicas estejam pautadas na agenda.

Embora modelos racionais sejam didaticamente bons, não estão necessariamente em consonância com a realidade.

Nem sempre o problema é claro, nem sempre os objetivos são claros ou coerentes com o problema, nem sempre existem soluções, nem sempre (ou quase nunca) é possível fazer uma comparação imparcial sobre alternativas de 
solução, nem sempre há tempo ou recursos para tomadas de decisão estruturadas. E o mais frustrante dessa história toda: frequentemente, após serem tomadas as decisões, as políticas públicas não se concretizam conforme idealizadas no momento do planejamento, seja por falta de habilidade administrativo-organizacional, seja por falta de legitimidade da decisão ou pela presença de interesses antagônicos entre aqueles que interferem na implementação da política pública (Secchi, 2014, p. 53).

Após esses apontamentos sobre a formulação da política pública, é importante compreender como a educação integral em tempo integral vem se constituindo como alternativa para o enfrentamento de determinados problemas sociais e educacionais.

Mais uma vez cabe destacar a singularidade de nosso sistema federativo que acaba por se traduzir em mais de 5.570 formas de organizar a educação brasileira e, consequentemente, essa diversidade repercutirá na opção ou não por formular políticas que contemplem a ampliação da jornada escolar e/ou educação em tempo integral.

Por exemplo, o Programa Mais Educação foi uma alternativa criada pelo governo federal para enfrentar o problema da qualidade do ensino fundamental e da ampliação das oportunidades educativas. Não é o único e nem o primeiro programa a fazer essa proposição. Inúmeras experiências de enfrentamento de tais problemas já foram criadas, pela via da educação em tempo integral ou não. No que se refere à primeira opção, várias ações de ampliação da jornada escolar já foram desenvolvidas por diferentes entes federativos ao longo da história da educação brasileira, para enfrentar diferentes problemas, geralmente relacionados à qualidade do ensino, mas também associados a questões sociais. Na década de 1950, pode-se citar a criação do Centro Educacional Carneiro Ribeiro, em Salvador, na Bahia, composto arquitetonicamente por Escolas-Classe e Escola-Parque (Éboli, 1983; Nunes, 2009). Na década de 1980, é possível citar os CIEPs (Cavaliere; Coelho, 2003); na década de 1990, os CAICs (Amaral Sobrinho; Parente, 1995). Mais recentemente, é possível enumerar uma série de políticas desenvolvidas por estados ou municípios brasileiros, entre elas: Projeto Escola de Tempo Integral, no estado de São Paulo, criado em 2005 (Cação, 2017); Programa Bairro-Escola, em Nova Iguaçu, Rio de Janeiro e Escola Integrada, em Belo Horizonte, Minas Gerais, ambos criados em 2006 (Moll, 2012).

Além disso, muitas vezes é possível encontrar ações governamentais concomitantes e até mesmo concorrentes para atingir o mesmo problema público, visto que essas ações podem atuar de forma colaborativa ou de forma concorrente, a depender da maneira como são articuladas. Até porque, como já foi citado anteriormente, nem sempre a política formulada surgiu para atacar um problema específico; muitas vezes a solução (política) surge antes mesmo de se definir o problema a ser atacado.

Com base no exposto, depreende-se que a ampliação da jornada escolar nem sempre é uma decisão tomada em meio a um diagnósti- 
Políticas de Educação Integral em Tempo Integral...

co educacional concreto. Há inúmeras ações de ampliação da jornada escolar e de educação integral em tempo integral desenvolvidas pelo Brasil afora. A educação em tempo integral tem sido apontada como alternativa a distintos problemas, embora muitas vezes seja uma solução em busca de um problema específico a enfrentar.

$\mathrm{O}$ fato é que, no âmbito nacional, exemplificando novamente, o Programa Mais Educação materializou uma tomada de decisão, a escolha de uma alternativa, a formulação de uma política: subsidiar escolas públicas de recursos financeiros e pedagógicos, de modo a possibilitar a ampliação de oportunidades educativas e induzir a ampliação da jornada escolar. Nas outras esferas (estaduais, distrital e municipais), a tomada de decisão em relação à ampliação da jornada escolar vem ocorrendo de várias formas, com ou sem o Programa Mais Educação, de forma articulada ou não a ele. A exemplificação é importante, inclusive para mostrar como as alternativas podem ser concorrentes ou colaborativas.

A formulação, assim como as demais fases da política pública, faz parte do processo decisório. E processo decisório não existe sem atores. No processo de decisão política, também chamado de jogo de poder por Lindblon (1981), cada um tem seu papel, existem regras que definem, por exemplo, o que pode e o que não pode, quem pode e quem não pode. No entanto, a próprias regras são definidas por quem tem mais poder, inclusive para mudá-las, quando necessário, ou para persuadir outros atores para que sigam determinadas opções político-administrativas.

Na fase de formulação é possível encontrar dois grupos de atores: atores formais (Legislativo e Executivo) e atores informais (movimentos sociais, organizações não governamentais, etc.) (Dias; Matos, 2012). Para Kingdon (2006b, p. 231), como já apontado, existem os participantes visíveis e invisíveis tanto na fase da agenda como na fase de elaboração de alternativas, que integra a formulação. Assim, na fase da formulação, os participantes invisíveis, entre eles “[...] acadêmicos, pesquisadores, burocratas de carreira, funcionários do Congresso e analistas que trabalham para grupos de interesse", têm papel importante na formulação de "alternativas, propostas e soluções [...]".

No que se refere à educação e, especificamente, à educação integral em tempo integral, é possível identificar tanto professores e pesquisadores da área integrando o Executivo $^{3}$, como também assessorando processos decisórios por meio de pesquisas encomendadas, por exemplo (Brasil, 2010b; 2013). Esse é um aspecto importante, na medida em que estão sendo ouvidos especialistas que estudam e pesquisam a temática, o que pode repercutir na formulação de políticas que melhor atendam a demandas educacionais específicas. No entanto, essa configuração não é uma regra. A participação de diferentes atores no processo decisório depende, como já se destacou, de uma série de variáveis. De acordo com Howlett, Ramesh e Perl (2013, p. 33), a tomada de decisão política “[...] participatória é desejável, não somente porque é mais democrática, mas também porque se alega que ela redunda em políticas melhores e em uma implementação mais eficaz [...]".

424 Educação \& Realidade, Porto Alegre, v. 43, n. 2, p. 415-434, abr./jun. 2018. 
A formulação de políticas de educação integral em tempo integral deveria estar articulada à perspectiva de uma formação humana o mais integral possível, ou seja, a mais oportunidades educacionais e, para tanto, a mais tempo de escola. No entanto, com base no exposto, nem sempre as políticas aqui citadas estão embasadas nessa concepção de formação humana e, muitas vezes, articulam-se apenas à melhoria de certos índices educacionais, supondo-se que a simples ampliação do tempo de escola levará à melhoria do desempenho em testes padronizados. Esse tipo de concepção e de suposição acaba por delinear, inclusive, modelos de políticas de educação em tempo integral, alguns deles focalizados no reforço dos conteúdos curriculares mínimos, limitando qualquer proposta de ampliação da formação humana.

\title{
Fase da Implementação: como as políticas de educação integral em tempo integral são implementadas
}

O processo de implementação pode ser entendido como a execução da política pública propriamente dita.

\begin{abstract}
Depois que um problema público conseguiu entrar na agenda política, depois que foram formuladas várias opções para resolvê-lo e depois que o governo estabeleceu os objetivos políticos e se decidiu por um curso de ação, ainda cabe a ele colocar a decisão em prática. O esforço, os conhecimentos e os recursos empregados para traduzir as decisões políticas em ações compreendem o estágio de implementação do ciclo político (Howlett; Ramesh; Perl, 2013, p. 179).
\end{abstract}

Jeffrey L. Pressman, Aaron B. Wildavsky, Carl Van Horn, Donald Meter, James Lester e Eugene Bardach são alguns dos estudiosos da fase de implementação (Viana, 1996; Rus Perez, 1998; Howlett; Ramesh; Perl, 2013; Secchi, 2014).

No entanto, é preciso superar a visão de que a fase da implementação é mera execução do que foi decidido na fase de formulação da política pública. Isso porque a “[...] implemementação não somente enseja execução, como também requer novas decisões. [...] as decisões não se encerram durante a formulação - se estendem por todo o período de vigência de uma política pública” (Rua, 2013, p. 91).

A análise da implementação de qualquer política pode contribuir não apenas para a visualização de questões técnicas ou erros de operacionalização, mas também propiciar elementos que evidenciem problemas na formulação da política pública. Mais ainda, pode ajudar a entender como ocorrem as interações entre os atores e o quanto são cruciais nos rumos das políticas públicas. Por isso, conforme Secchi (2014), na análise do processo de implementação, as pessoas e as organizações, seus interesses, comportamentos e competências, bem como os recursos financeiros, materiais e políticos são elementos básicos a serem considerados. 
Políticas de Educação Integral em Tempo Integral...

Para análise da implementação das políticas públicas, têm sido disseminados dois modelos que se articulam diretamente às concepções e às relações estabelecidas entre formulação e implementação: modelo top-down (de cima para baixo), que enfatiza a relevância do momento da formulação no sucesso ou fracasso das políticas; e modelo bottom-up (de baixo para cima), que enfatiza a relevância dos atores implementadores e suas interações no processo de (re)definição das decisões tomadas anteriormente (Secchi, 2014; Rus Perez, 1998; Rua, 2013).

Para além desses dois modelos, há uma terceira perspectiva denominada de híbrida, a partir da qual é possível aproveitar elementos analíticos de ambos os modelos:

\begin{abstract}
A abordagem top-down começa com as decisões do governo, examina o quanto dessas decisões os administradores de fato executam e procura encontrar as razões subjacentes à implementação efetivada. A abordagem bottom-up meramente começa na outra extremidade da cadeia de comando da implementação e exige que se leve em consideração os assim chamados implementadores de balcão ou da linha de frente (street-level) (Howlett; Ramesh; Perl, 2013, p. 184).
\end{abstract}

Ao longo do desenvolvimento dos estudos sobre implementação, foram sendo sistematizados alguns fatores que influenciam no processo de implementação da política pública, tais como "[...] disponibilidade e qualidade dos recursos humanos e materiais, estrutura e a dinâmica das regras organizacionais (formais e informais), fluxo e disponibilização de informações” (Lima; D’Ascenzi, 2013, p. 106). Além disso, cabe destacar que muitos fatores estão associados aos atores implementadores: papéis, decisões, disponibilidade, interações e negociações.

Feitas essas considerações, é importante compreender como as políticas de educação integral em tempo integral estão sendo implementadas e quais elementos são imprescindíveis para a análise de seu processo de implementação.

Partindo de uma perspectiva de análise híbrida, conforme caracterizada anteriormente, analisar a implementação de um determinado programa de educação integral em tempo integral no âmbito de determinado ente federativo ou de uma escola requer identificar não apenas os objetivos da política inicialmente formulados (incluindo-se meios e instrumentos), como também identificar os principais atores envolvidos nesse processo e as relações estabelecidas entre eles, incluindo os recursos de que dispõem (parte ou não da política) para atingir os objetivos esperados e/ou reformulados.

Os estudos sobre políticas de educação integral em tempo integral podem concentrar-se em níveis mais estratégicos e estruturais da política pública, por exemplo, no âmbito dos órgãos responsáveis por sua formulação, a exemplo do Ministério da Educação e das Secretarias Estaduais e Municipais de Educação, órgãos responsáveis pela gestão das políticas educacionais nos sistemas de ensino, buscando captar as articulações entre política formulada e política implementada. 
Tendo em vista o sistema federativo brasileiro, conforme destacado anteriormente, é possível desenvolver análises que privilegiem as articulações entre formulação e implementação de políticas de educação em tempo integral num mesmo ente federativo ou aquelas que focalizam ações e programas formulados e implementados por entes federativos diferentes, a exemplo do Programa Mais Educação.

O Programa Mais Educação, formulado pelo governo federal, é implementado por escolas públicas estaduais, distritais e municipais de todo o país: a formulação e a implementação da política pública ocorreram/ocorrem em dois momentos bem distintos e realizados por atores diferentes. Disso, pode-se depreender que, na hipótese do Programa Mais Educação não atingir seus objetivos, haveria erro no processo de formulação em não prever fatores que poderiam interferir na boa execução do programa. Ainda que esse aspecto possa ser considerado e ser muito útil a outras políticas a serem formuladas posteriormente na área, concebe-se que a previsibilidade e o controle não atingem seu ponto máximo diante das variáveis que podem interferir na dinâmica dos atores no processo de implementação. Essa é, portanto, uma possibilidade de análise que poderia se somar a outras perspectivas que concebem a fase de implementação como uma continuidade do processo decisório.

Assim, partindo de uma concepção que compreende a implementação da política pública como espaço também para a sua própria reformulação, a implementação do Programa Mais Educação no âmbito dos estados, Distrito Federal e municípios não seria mera reprodução das decisões tomadas na fase de formulação. Nessa concepção, há espaços para que escolas e entes federativos considerem a sua realidade e façam as adaptações necessárias e possíveis. Isso porque, nesse modelo, “[...] o formato que a política pública adquiriu após a tomada de decisão não é definitivo, e a política pública é modificável por aqueles que a implementam no dia a dia" (Secchi, 2014, p. 61).

Diante dessa concepção e desse modelo de análise do processo de implementação, compreende-se a limitação de afirmações que julgam o sucesso de uma política apenas por seu desenho ou por seus objetivos inicialmente delimitados. Há muitas variáveis que interferem na boa implementação de uma política pública, para além do que seus formuladores podem prever.

O Programa Mais Educação, mais uma vez utilizado como exemplo, repassa recursos às escolas a título de ressarcimento de despesas com monitores voluntários. Muitas escolas, por várias razões, optaram por não ter voluntários e utilizar profissionais efetivos e/ou contratados para viabilização das oficinas do programa. O exemplo mostra uma redefinição da política realizada no âmbito do ente federativo ao qual a escola está vinculada. Essa é uma variável que poderá interferir nos resultados do Programa; e os resultados da política (satisfatórios ou não) não poderão ser atribuídos apenas aos seus formuladores ou aos seus implementadores, sem uma análise pormenorizada das variáveis que interferem no processo de implementação. 
Políticas de Educação Integral em Tempo Integral...

No entanto, ainda paira na gestão pública brasileira a concepção de que muitos programas foram muito bem formulados, porém não se forneceu a capacitação necessária aos seus implementadores. Nessa perspectiva, a culpa de determinada política não chegar aos resultados que deveria chegar não seria dos formuladores e sim dos implementadores. É preciso investir na superação da dicotomia entre formulação e implementação. A incorporação de atores implementadores e dos próprios beneficiários no processo de formulação de políticas educacionais parece ser uma perspectiva democrática e participativa que avança no sentido de melhor atender às demandas educacionais.

\section{Fase da Avaliação: como as políticas de educação integral em tempo integral são avaliadas}

A avaliação da política pública pode ser conceituada como a fase da política na qual "[...] o processo de implementação e o desempenho da política pública são examinados com o intuito de conhecer melhor o estado da política e o nível de redução do problema que a gerou" (Secchi, 2014, p. 63).

No Brasil, alguns autores e pesquisadores preocuparam-se em estudar essa fase da política pública, entre eles, Arretche (1998), que apresenta tendências de avaliação de políticas públicas; Faria (2005), que mostra o caráter gerencialista das políticas de avaliação de políticas públicas; e Trevisan e Van Bellen (2008), que apresentam um histórico da literatura sobre políticas públicas e, em especial, da avaliação de políticas.

A avaliação é uma ação feita com base em valores, julgamentos, critérios e parâmetros. São esses elementos que irão julgar se determinada política pública funcionou de forma positiva ou negativa na solução de determinado problema. Por isso, a avaliação política é compreendida como "[...] etapa preliminar e preparatória do que convencionalmente se chama Avaliação de Política” (Figueiredo; Figueiredo, 1986, p. 108).

Apesar de a avaliação ter um aspecto técnico e, assim como em outras fases do ciclo da política, receber forte herança do racionalismo e do positivismo, é preciso compreender que a avaliação da política não é neutra, é limitada e seus resultados articulam-se aos seus responsáveis e às suas opções teórico-metodológicas e que, por sua vez, não estão isentos do aspecto político. Por isso, conforme Howlett, Ramesh e Perl (2013, p. 200), a avaliação da política pode "[...] mascarar ou esconder certos fatos que o governo teme que venham a denegri-lo" ou levar "[...] a conclusões que o pintem em cores mais favoráveis”. Daí a importância de entender os benefícios e também os limites da avaliação de políticas públicas.

Entre os critérios utilizados para realizar avaliação de políticas públicas estão: eficiência, eficácia, impacto, sustentabilidade, análise custo-efetividade, satisfação do beneficiário e equidade (Costa; Castanhar, 2003). Com base nesses critérios, é possível fazer uma avaliação com diferentes perspectivas: “[...] uma perspectiva mais gerencial ou 
técnica, uma perspectiva política ou uma perspectiva mais classicamente jurídica ou legal” (Subirats, 1994, p. 140, tradução nossa) ${ }^{4}$.

A depender do aspecto temporal, do objeto de estudo, dos objetivos definidos e das técnicas e métodos empregados, a avaliação de políticas ou programas sociais pode ser classificada de diferentes formas. Assim, na tipologia de avaliação de políticas, pode-se encontrar: avaliação ex-ante e ex-post (em função do momento em que a avaliação é realizada); avaliação externa e interna (em função de quem realiza a avaliação); avaliação de metas, avaliação de processos e avaliação de impacto (em função do conteúdo da avaliação e do momento em que é realizada) (Cohen; Franco, 2003; Costa; Castanhar, 2003; Figueiredo; Figueiredo, 1986).

Há lacunas no campo da avaliação de políticas educacionais, muitas vezes em função das dificuldades de aceitação de determinados critérios na condução de avaliações. Outras vezes, referem-se às dificuldades de se articular objetivos de avaliação a adequados métodos e técnicas de avaliação. Outras dificuldades ainda ocorrem por resistências ao emprego de determinados métodos e técnicas de avaliação de políticas educacionais já utilizados em outras áreas. O fato é que existem muitas resistências para a realização de avaliações de políticas educacionais e essa lacuna certamente afeta a visualização de seus resultados efetivos.

Diante do exposto, é importante verificar se e como as políticas de educação integral em tempo integral têm sido avaliadas. Primeiramente, cabe destacar que várias políticas de educação integral em tempo integral já foram formuladas, implementadas, deixaram de existir e sequer foram avaliadas, o que demarca o nosso histórico de descontinuidades políticas ou, no mínimo, denota fragilidades na argumentação sobre os motivos de dar ou não continuidade a certas políticas e programas. Tomando-se como pressuposto a relevância da avaliação tanto do ponto de vista técnico como político, pode-se avaliar uma política de educação integral em tempo integral com base em diferentes critérios.

É possível desenvolver um estudo com foco na avaliação de metas, ou seja, que tenha como objetivo “[...] medir o grau de êxito que um programa obtém com relação ao alcance de metas previamente estabelecidas" (Costa; Castanhar, 2003, p. 979). Com base nessa opção, é possível analisar documentos que originaram determinado programa e sua fundamentação teórico-legal e desenvolver instrumentos que comparem o previsto e os resultados.

Pode-se também realizar um estudo com foco na avaliação de processos, ou seja, com o objetivo de "[...] medir a cobertura do programa social; estabelecer o grau em que está alcançando a população beneficiária; e, principalmente, acompanhar seus processos internos". Por meio desse tipo de avaliação é possível “[...] detectar possíveis defeitos na elaboração dos procedimentos, identificar barreiras e obstáculos à sua implementação [...]” (Costa; Castanhar, 2003, p. 979). Esse tipo de estudo pode, assim, tanto identificar o nível de cobertura de determi- 
Políticas de Educação Integral em Tempo Integral...

nada política (alunos, escolas, estados, regiões) como trazer à tona elementos que se constituem como obstáculos à implementação da política e, portanto, aos resultados esperados.

Outra opção pode ser a realização de estudos de avaliação de impacto, cujo objetivo está em captar os “[...] efeitos do programa sobre a população-alvo e tem, subjacente, a intenção de estabelecer uma relação de causalidade entre a política e as alterações nas condições sociais" (Figueiredo; Figueiredo, 1986, p. 111). Ainda que se acredite no limite desse tipo de avaliação na área de Ciências Humanas, tendo em vista a dificuldade de isolar variáveis e estabelecer relações causais que levem a afirmações que atestem que determinado programa (x) foi o único responsável por modificar determinada realidade/sujeito/objeto (y), existem estudos, geralmente desenvolvidos fora da área de educação, que têm se arriscado a fazer avaliações de impacto de programas de ampliação da jornada escolar (Xerxenevsky, 2012; Pereira, 2011; Fundação Itaú Social, 2015).

O fato é que ainda não há uma tradição de desenvolver estudos de avaliação de políticas na área da educação. O desenvolvimento desses estudos poderá trazer novas perspectivas metodológicas que melhor traduzam as especificidades da área e melhor contribuam para a visualização dos resultados das políticas.

\section{Considerações Finais}

Há alguns anos estudando políticas públicas, são visíveis as lacunas no que se refere ao desenvolvimento de elementos teórico-metodológicos que permitam uma análise mais apurada das políticas educacionais. Para além de uma visão racional e técnica, a análise do ciclo da política pública deve permitir ao pesquisador a compreensão dos diferentes fatores que interferem no processo de policy making. Por isso, é essencial, entre outros elementos, captar a dinâmica do processo decisório, de produção da política pública e a forma como os atores se articulam no desenvolvimento do jogo político.

O presente estudo buscou sistematizar alguns elementos para a análise das políticas de educação integral em tempo integral, à luz do ciclo das políticas públicas. Mostrou que a temática está presente na agenda político-educacional e que podem ser muitos os problemas públicos de ordem social ou educacional que justificam ações de ampliação da jornada escolar. Porém são muitos os determinantes que interferem na manutenção da temática na agenda e na formulação ou não de políticas para a área.

O estudo evidenciou ainda que em cada fase do ciclo da política pública há atores com maior ou menor poder decisório, e isso poderá repercutir nos tipos de escolhas que estão sendo feitas em termos de políticas de educação integral em tempo integral. A força do Legislativo e do Executivo na agenda e na formulação é evidente. Assim, o Ministério da Educação e as Secretarias de Educação em todas as esferas de governo são os principais atores na formulação das políticas de educa-

430 Educação \& Realidade, Porto Alegre, v. 43, n. 2, p. 415-434, abr./jun. 2018. 
ção integral em tempo integral. Apesar disso, enfatizamos o risco de se interpretar a implementação como mera reprodução das decisões tomadas na fase da formulação. Os implementadores, diante de realidades, recursos e estruturas específicas tomam decisões cotidianamente, o que pode ser interpretado como ricas possibilidades para reformulações do processo decisório. E é justamente por isso que a política não pode ser avaliada apenas a partir de uma relação unidirecional e causal. A avaliação de qualquer política de educação integral em tempo integral precisa considerar o desenho da política, mas também os fatores que interferiram em seu processo, o que repercutirá nos resultados (esperados ou não).

Várias pesquisas já foram realizadas tendo como objeto de estudo determinada política de educação integral em tempo integral. As possibilidades de captar esse objeto são diversas a depender dos interesses e objetivos do pesquisador. O presente ensaio é um convite para que pesquisas e estudos focalizem as políticas de educação integral em tempo integral na perspectiva da política pública e sejam pensados a partir de outros enfoques analíticos, a exemplo do ciclo da política pública ou a partir de uma determinada fase da política. É também um convite para que, diante dessa opção analítica, sejam construídos metodologias e instrumentos que melhor captem a dinâmica da política educacional e possam subsidiar gestores no processo de tomada de decisão no campo da educação.

Recebido em 27 de janeiro de 2016 Aprovado em 29 de maio de 2017

\section{Notas}

1 No original: "[...] whatever governments choose to do or not do".

2 No original: "Policy analysis is finding out what governments do, why they do it, and what difference, if any, it makes".

3 Pode-se citar o exemplo de Jaqueline Moll, professora da Faculdade de Educação da Universidade Federal do Rio Grande do Sul, pesquisadora e autora de artigos e livros relacionados à temática. A professora atuou como Diretoria de Educação Integral, Direitos Humanos e Cidadania da Secretaria de Educação Continuada, Alfabetização e Diversidade do Ministério da Educação (2007 a 2011) e como Diretora de Currículos e Educação Integral da Secretaria de Educação Básica do Ministério da Educação (2011-2013).

4 No original: “[...] una perspectiva más gerencial o técnica, una perspectiva política o una perspectiva más clásicamente jurídica o legal”.

\section{Referências}

AMARAL SOBRINHO, José; PARENTE, Marta Maria de Alencar. CAIC: solução ou problema? Texto para Discussão, Brasília, n. 363, jan. 1995. Disponível em: <http://www.ipea.gov.br/agencia/images/stories/PDFs/TDs/td_0363.pdf>. Acesso em: 15 maio 2017.

ARRETCHE, Marta Teresa da Silva. Tendências no Estudo sobre Avaliação. In: RICO, Elizabeth Melo (Org.). Avaliação de Políticas Sociais: uma questão em debate. São Paulo: Cortez, 1998. P. 29-39.

Educação \& Realidade, Porto Alegre, v. 43, n. 2, p. 415-434, abr./jun. 2018. 
ARROYO, Miguel Gonzales. Imagens Quebradas: trajetórias e tempos de alunos e mestres. Petrópolis, RJ: Vozes, 2004.

BRASIL. Presidência da República. Lei no 9.394, de 20 de dezembro de 1996. Estabelece as diretrizes e bases da educação nacional. Diário Oficial da União, Brasília, 1996. Disponível em: <http://www6.senado.gov.br/sicon/ExecutaPesquisaLegislacao.action>. Acesso em: 30 jun. 2015.

BRASIL. Lei n. 10.172, de 09 de janeiro de 2001. Aprova o Plano Nacional de Educação e dá outras providências. Diário Oficial da União, Brasília, 2001. Disponível em: <https://www.planalto.gov.br/ccivil_03/leis/leis_2001/l10172.htm>. Acesso em: 10 abr. 2017.

BRASIL. Emenda Constitucional n. 53, de 19 de dezembro de 2006. Dá nova redação aos arts. $7^{\circ}$, 23, 30, 206, 208, 211 e 212 da Constituição Federal e ao art. 60 do Ato das Disposições Constitucionais Transitórias. Diário Oficial da União, Brasília, 2006. Disponível em: <http://www.planalto.gov.br/ccivil_03/constituicao/emendas/emc/emc53.htm>. Acesso em: 18 maio 2017.

BRASIL. Portaria Interministerial no 17, de 24 de abril de 2007. Institui o Programa Mais Educação, que visa fomentar a educação integral de crianças, adolescentes e jovens, por meio do apoio a atividades sócio-educativas no contraturno escolar. Brasília, 2007a. Disponível em: <http://portal.mec.gov.br/arquivos/pdf/mais_educacao.pdf >. Acesso em: 30 jun. 2015.

BRASIL. Plano de Desenvolvimento da Educação: razões e princípios. Brasília, DF: MEC, 2007b. Disponível em: <http://portal.mec.gov.br/arquivos/livro/index.htm>. Acesso em: 14 set. 2015.

BRASIL. Decreto no 7.083, de 27/01/2010. Dispõe sobre o Programa Mais Educação. Diário Oficial da União, Brasília, 2010a. Disponível em: <http://www.planalto.gov.br/ccivil_03/_Ato2007-2010/2010/Decreto/D7083.htm>. Acesso em: 30 jun. 2015.

BRASIL. Ministério de Educação. Educação Integral/Educação Integrada e(m) Tempo Integral: concepções e práticas na educação brasileira - mapeamento das experiências de jornada escolar ampliada no Brasil. Brasília: MEC; SECAD, 2010b.

BRASIL. Ministério de Educação. Programa Mais Educação: impactos na educação integral e integrada. Brasília: MEC, 2013.

BRASIL. Lei no 13.005, de 25 de junho de 2014. Aprova o Plano Nacional de Educação - PNE e dá outras providências. Diário Oficial da União, Brasília, 2014. Disponível em: <http://www.planalto.gov.br/ccivil_03/_Ato2011-2014/2014/ Lei/L13005.htm>. Acesso em: 06 jul. 2015.

CAÇÃO, Maria Izaura. Educação Integral em Tempo Integral no Estado de São Paulo: tendências, Educação em Revista, Marília, v. 18, Edição Especial, p. 95-120, 2017.

CAVALIERE, Ana Maria; COELHO, Lígia Martha. Para Onde Caminham os CIEPs? Uma Análise Após 15 anos. Cadernos de Pesquisa, São Paulo, n. 119, p. 147-174, jul. 2003.

COHEN, Ernesto; FRANCO, Rolando. Avaliação de Projetos Sociais. Petrópolis: Vozes, 2003.

COSTA, Frederico Lustosa da; CASTANHAR, José Cezar. Avaliação de Programas Públicos: desafios conceituais e metodológicos. Revista de Administração Pública, Rio de Janeiro, v. 37, n. 5, p. 969-992, set./out. 2003.

DIAS, Reinaldo; MATOS, Fernanda. Políticas Públicas: princípios, propósitos e processos. São Paulo: Editora Atlas, 2012.

DYE, Thomas R. Understanding Public Policy. Pearson: New Jersey, 2008.

432 Educação \& Realidade, Porto Alegre, v. 43, n. 2, p. 415-434, abr./jun. 2018. 
ÉBOLI, Terezinha. Uma Experiência de Educação Integral. Rio de Janeiro: Faperj, 1983. Disponível em: <http://www.dominiopublico.gov.br/download/ texto/me001840.pdf>. Acesso em: 15 maio 2017.

FARIA, Carlos Aurélio Pimenta de. A Política da Avaliação de Políticas Públicas. Revista Brasileira de Ciências Sociais, São Paulo, v. 20, n. 59, p. 97-109, out. 2005. FIGUEIREDO, Marcus Faria; FIGUEIREDO, Argelina Maria Cheibub. Avaliação Política e Avaliação de Políticas: um quadro de referência teórica. Análise e Conjuntura, Belo Horizonte, v. 1, n. 3, p. 107-127, set./dez. 1986.

FUNDAÇ̃̃O ITAÚ SOCIAL. O Programa Mais Educação - Ministério da Educação. Relatório de Avaliação Econômica e Estudos qualitativos. Avaliação econômica de projetos sociais. São Paulo: Fundação Itaú Social, 2015. Disponível em: $<$ http://www.redeitausocialdeavaliacao.org.br/wp-content/uploads/2015/11/ relat_Mais_Educa\%C3\%A7\%C3\%A3o_COMPLETO_20151118.pdf>. Acesso em: 18 maio 2017

HOWLETT, Michael; RAMESH, Mishra; PERL, Anthony. Política Pública: seus ciclos e subsistemas - uma abordagem integradora. Rio de Janeiro: Elsevier, 2013.

JOBERT, Bruno; MÜLLER, Pierre. L'etat en Action: politiques publiques et corporatismes. Paris: Presses Universitaires de France, 1990.

KINGDON, John. Como Chega a Hora de Uma Ideia? In: SARAVIA, Enrique; FERRAREZI, Elisabete. Políticas Públicas - Coletânea. Brasília: ENAP, 2006a. P. 219224.

KINGDON, John. Juntando as Coisas. In: SARAVIA, Enrique; FERRAREZI, Elisabete. Políticas Públicas - Coletânea. Brasília: ENAP, 2006b. P. 225-245.

LIMA, Luciana Leite; D’ASCENZI, Luciano. Implementação de Políticas Públicas: perspectivas analíticas. Revista de Sociologia Política, Curitiba, v. 21, n. 48, p. 101-110, dez. 2013

LINDBLON, Charles. O Processo de Decisão Política. Brasília, DF: UNB, 1981.

MOLL, Jaqueline (Org.). Caminhos da Educação Integral no Brasil. Porto Alegre: Penso, 2012.

NUNES, Clarice. Centro Educacional Carneiro Ribeiro: concepção e realização de uma experiência de educação integral no Brasil. Em Aberto, Brasília, v. 22, n. 80, p. 121-134, abr. 2009.

PARENTE, Cláudia da Mota Darós. A Construção dos Tempos Escolares. Educação em Revista, Belo Horizonte, v. 26, n. 2, p. 135-156, ago. 2010.

PARENTE, Cláudia da Mota Darós. A Construção dos Tempos Escolares. São Cristóvão, SE: Editora UFS, 2015.

PARENTE, Cláudia da Mota Darós. Construindo uma Tipologia das Políticas de Educação Integral em Tempo Integral. Roteiro, Joaçaba, v. 41, n. 3, p. 563-586, set./dez. 2016a.

PARENTE, Cláudia da Mota Darós. Programa Mais Educação e Modelos de Educação em Tempo Integral. Cadernos de Educação, Pelotas, n. 54, p. 152-169, maio/set. 2016b.

PARENTE, Cláudia da Mota Darós. A Construção da Meta de Educação em Tempo Integral do Plano Nacional de Educação (2014). Educação em Revista, Marília, v. 18, Edição Especial, p. 23-42, 2017.

PARENTE, Cláudia da Mota Darós; RUS PEREZ, José Roberto; MATTOS, Maria José Viana Marinho de. Avaliação, Monitoramento e Controle Social: contribui- 
Políticas de Educação Integral em Tempo Integral...

ção à pesquisa e à política educacional. In: PARENTE, Cláudia da Mota Darós; PARENTE, Juliano Mota (Org.). Avaliação, Política e Gestão da Educação. São Cristóvão, SE: 2012. P. 15-31.

PEREIRA, Guilherme Costa. Uma Avaliação de Impacto do Programa Mais Educação no Ensino Fundamental. 2011. Dissertação (Mestrado em Políticas Públicas, Estratégia e Desenvolvimento) - Universidade Federal do Rio de Janeiro, Rio de Janeiro, 2011.

RUA, Maria das Graças. Para Aprender Políticas Públicas. Brasília, DF: IGEPP, 2013.

RUS PEREZ, José Roberto. Avaliação do Processo de Implementação: algumas questões metodológicas. In: RICO, Elizabeth Melo (Org.). Avaliação de Políticas Sociais: uma questão em debate. São Paulo: Cortez, 1998. P. 65-73.

SECCHI, Leonardo. Políticas Públicas: conceitos, esquemas de análise, casos práticos. São Paulo: Cengage Learning, 2014.

SOUZA, Celina. Políticas Públicas: uma revisão da literatura. Sociologias, Porto Alegre, v. 8, n. 16, p. 20-45, jul./dez 2006.

SUBIRATS, Joan. Análisis de Políticas y Eficacia de la Administración. Madrid: MAP/INAP, 1994.

SUBIRATS, Joan. Definición Del Problema. Relevancia Pública y Formación de la Agenda de Actuación de los Poderes Públicos. In: SARAVIA, Enrique; FERRAREZI, Elisabete. Políticas Públicas - Coletânea. Brasília: ENAP, 2006. P. 199-218.

TREVISAN, Andrei Pittol; VAN BELLEN, Hans Michael. Avaliação de Políticas Públicas: uma revisão teórica de um campo em construção. Revista de Administração Pública, Rio de Janeiro, v. 42, n. 3, p. 529-50, maio/jun. 2008.

VIANA, Ana Luiza. Abordagens Metodológicas em Políticas Públicas. Revista Brasileira de Administração Pública, Rio de Janeiro, v. 30, n. 2, p. 5-43, mar./ abr. 1996.

XERXENEVSKY, Lauren Lewis. Programa Mais Educação: avaliação do impacto da educação integral no desempenho de alunos no Rio Grande do Sul. 2012. Dissertação (Mestrado em Economia do Desenvolvimento) - Pontifícia Universidade Católica do Rio Grande do Sul, Porto Alegre, 2012.

Cláudia da Mota Darós Parente é professora da Universidade Estadual Paulista (UNESP), do Departamento de Administração e Supervisão Escolar (DASE) e do Programa de Pós-Graduação em Educação de Presidente Prudente. Líder do Grupo de Pesquisa e Avaliação de Políticas Educacionais (GAPE). Pedagoga pela Universidade de São Paulo (USP), Mestre e Doutora em Educação pela Universidade Estadual de Campinas (Unicamp). E-mail: claudiadaros@marilia.unesp.br 